\title{
柴达木盆地荒漠化土地的成因与及治理对策
}

韩万义

青海省林业草原规划院

DOI:10.32629/ems.v1i1.286

[摘要] 本文分析了柴达木盆地荒漠化土地的成因与发展趋势及荒漠化土地的危害,并提出了柴达木盆地的开发利用、防沙治沙的对策。 [关键词] 荒漠化; 发展趋势; 防沙治沙

柴达木盆地位于青藏高原东北部,东经 $91^{\circ}-98^{\circ}$, 北纬 $35^{\circ}$ -39 之间,南临昆仑山,北依祁连山,西北部边缘为阿尔金山,属较 大的内陆盆地。盆地东西长 $88,850 \mathrm{~km}$,南北宽 $250-350 \mathrm{~km}$ 。盆地沙 漠属青藏高原干旱高寒荒漠,是我国荒漠分布最高的地区。呈现风 蚀、沙丘、戈壁、盐湖和盐土平原相互交错的分布特点。柴达木盆地 的荒漠面积 $12,129,911.4 \mathrm{hm}^{2}$ 。其中流动沙丘 $1,635,797.6 \mathrm{hm}^{2}$, 半固 定沙丘 $1,168,772.7 \mathrm{hm}^{2}$, 固定沙丘 $91,626.7 \mathrm{hm}^{2}$, 风蚀残丘 $2,045,341.3 \mathrm{hm}^{2}$, 戈壁 4,587,375.9hm², 盐漠 $1,812,892.3 \mathrm{hm}^{2}$, 重盐漠地 $6,176.0 \mathrm{hm}^{2}$, 潜在荒漠化土地 $803,106.8 \mathrm{hm}^{2}$,农田 $1,658.0 \mathrm{hm}^{2}$ 。

1 荒漠化成因

柴达木盆地荒漠的形成受多种因素影响。主要成因可分为自 然因素和人为因素。
1.1 自然因素

1.1.1 地质构造

荒漠形成与地质发展史密切关系。柴达木盆地是古老的台块, 有前震旦纪的结晶岩组成它的禇皱基底, 上部为中生代和第四纪 沉积物所覆盖。经历多次造山运动,形成四分五裂的地形地貌。中 生代三叠纪之后开始活化,一直延续到现在。前期表现在急剧沉陷, 堆积了数千米第三系。到第四纪初期,出现明显差异,表现为以基底 断块为基础的凹陷和隆起。盆地西部及北部一些地区相对隆起,东 南部边缘一些地区继续下陷。同时伴有旋卷运动,使新生代岸层发 生了雁式禇坡,反 "S" 轴线构造及帚状断裂等。柴达木盆地的地质 构造分为:昆仑山禇皱带; 祁连山福皱带; 阿尔金山断块及南阿尔 金山禇皱带。既然荒漠是高原的隆起而形成的,那么,当抬外的过程
护企业的形象和利益,忠实语党,忠实于企业。因此,要开展相关的 教育工作。但值得注意的是," 忠实 " 的建立需要员工从内心深处 自觉遵守,让他们自觉为企业做贡献。应通过对广大员工的尊重进 行 " 忠实 " 的建立,建立人性化的新型管理模式,党员干部要关注 员工的发展,努力维护员工的权益,从而激发他们工作的创造性和 积极性; 要保障员工的民主权利, 促进党内民主制度化建设。此外, 让员工参与到热力企业的管理事务当中去, 了解企业的状况及未 来发展方向,从而自觉维护和遵守热力企业的相关规章制度。

3.3 建立学习型党组织

热力企业要把建立学习型党组织做为党政工作的重中之重, 热力 企业的发展面临着一个全新的发展领域,因此,党员首先要发挥模 范带头作用,加强学习,不断掌握先进的管理方法与技术,不断提高 自己,从而促进整个组织水平的提高。具体来说, 首先, 要健全学习 机制,这是党组织建立最根本的基础。用制度的约束力量来督促员 工去学习,从而建立起学习型党组织。此外,要建立良好的激励机 制,实行绩效考核制度,并将其应用到学习领域,这样更能提高员工 学习的效率。其次,要进行经验总结。对以往的经验进行总结和借 鉴,对学习型党组织的建立也颇为有利。热力企业在进行党政工作 时,必须要有计划、有组织地进行, 同时,也要定期做工作总结及工 作汇报,学习其中好的方面,纠正不理想的方面,并将其应用于实际 的工作当中去。

3.4 强化党支部标准化管理

目前,党组织工作面临着许多前所未有的新情况、新课题,现实 要求党的组织只能在继承中改革,在改革中创新,在创新中发展,在 发展中加强。因为只有加强党的基层组织建设,加强党的标准化管 理工作,才能坚持和健全党的组织原则和组织制度; 才能加强党的 干部队伍建设; 才能发展的、壮大和巩固党员队伍; 才能把党的组
织活动程序化、规范化、制度化; 才能不断总结党的组织工作经验、 探索新阶段党的基层组织建设的新路子, 开创党的建设的新局 面。

在热力公司党组织体系中, 党支部是把党员组织起来的最直 接的形式,是党的整个组织体系的基石,是党在企业基层组织中的 战斗堡垒。改革的推进、企业的发展和稳定,都要依靠基层党支部 的战斗堡垒作用和广大党员先锋模范作用的充分发挥。在新的历 史时期,要把党建设成为领导企业经济建设的坚强核心,就必须把 基层党支部建设成为团结和带领职工进行改革和建设的战斗堡 垒,把党的领导核心作用发挥好,把基层党支部的战斗堡垒作用发 挥好,把广大共产党员的先锋模范作用发挥好。只有基层党支部充 满活力,生机勃勃, 整个党组织才能坚强有力, 朝气蓬勃。实践证明, 热力企业党支部标准化管理对党支部建设能够起到极大的推动作 用。

\section{4 结束语}

随着我国经济的不断发展，热力企业本身的政治思想方向的 把握更显重要。新的时期、新的模式下,党政工作要做到与时俱进。 因此,要求热力企业的党政工作者在实践中不断探索和完善,寻找 到加强党政工作的新途径, 切实推动热力企业的快速稳定发展, 为 热力企业发展提供一定的保障。

[参考文献]

[1] 虞蓉.浅谈创新供热企业基层党建工作的方法 [J]. 经济 研究导刊 2013(9):229-230.

[2] 杜力.试论热力集团加强和改进基层党建工作的策略 [J]. 东方企业文化,2015(09):341.

[3]张建忠.浅谈企业基层党建工作中存在的问题及对策 [J]. 新西部: 中旬・理论,2015(11):69-69. 
尚未终止时,大气环流变化着,气候不会发生质的变化,干旱程度仍 在加剧,荒漠化自然还在发展。

1.1.2 地貌

按其成因柴达木盆地地貌可划为侵蚀构造高山地形; 剥蚀构 造中低山地形; 剥蚀构造地山丘陵地形和堆积地形。据宋德明 (1989 年)提出的划分方法, 可将柴达木盆地地貌划为 4 个各具特 征部分。第一是西柴达木干燥剥蚀高平原。上有甘森、台吉乃尔湖、 搭布逊湖至锡铁山一线以西的柴达木盆地东部, 新第三纪以来的 新构造运动使这里缓慢隆起, 形成以剥蚀作用占优势的平原和丘 陵, 气候极度干燥, 风力及强, 干燥剥蚀戈壁和风蚀地形分布很广, 有 一部分是风积沙丘地貌。西柴达木盆地的东北部, 海拔 2700-3100m, 主要是第三纪地层形成的线状背斜, 形成干燥剥蚀丘 陵地貌。向斜凹地中分布着洪积砾石和盐土硬壳, 丘陵相对高度 50-300m。风蚀土丘和风积沙丘也相当发育。近昆仑山麓有宽 10 余公里的洪积砾石平原, 上覆新月形沙丘。西部有格孜库里湖盆地, 海拔 $2750 \mathrm{~m}$ 。四周山麓向盆地中心发育洪积平原。冲积湖积平原及 盐土平原, 在中心形成格孜库里湖草滩。第二是北柴达木干燥剥蚀 中山和洪积湖积平原。干燥剥蚀中山靠近祁连山有断续的山地组 成, 自西向东为绿梁山、锡铁山和埃姆尼克山, 山地海拔 $3500 \mathrm{~m}$ 左 右, 相对高度 300-500m。与祁连山之间有一系列小型构造盆地, 如 鱼片、大柴旦、小柴旦、德令哈、都兰盆地等。盆地多以湖泊为中心, 分布着冲积洪积平原。德令哈盆地西面和南面, 有第三纪地层形成 的北斜构造, 径分割破碎, 造成垄刚丘陵, 也有厚层黄土分布。第三 是柴达木盆地东南部冲积平原, 西起甘森, 东至察汗乌苏, 长 $5000 \mathrm{~km}$, 海拔 2550-3100m。昆仑山麓的盆地南部为冲积洪积倾斜 平原, 宽 10-20km。东部的德日尔和察汗乌苏一带, 黄土发育良好。 冲积洪积平原以北是湖积平原。最初宽 20-30 km 的冲积湖积粉状 沙质平原,盐渍化较轻, 在灌溉条件下可开垦耕地。在此以北为盐土 平原, 地面盐分聚积, 形成盐土硕売, 有些地方沙丘分布, 盐土埋于地 下。再往北为盐渍平原, 盐土硕厚 5-10m, 以下为盐矿结晶体, 厚度 深, 㤱量丰富。第四是柴达木东缘山地。由之古界和古生代变质岩 以及少量花岗岩组成。山区内部较宽, 山坡以侵蚀为主, 西坡有风积 分沙土分布, 最西段因风沙掩盖, 形成许多岛山。南部山峰高大 $5800 \mathrm{~m}$, 有冰川侵蚀遗迹。第五是鄂拉山北面有茶卡盆地和惠渠盆 地,前者是冲积洪积平原, 中心为茶卡湖,面积 $230 \mathrm{~km}^{2}$ 。

1.1.3 气候因素

柴达木盆地四周环山, 是一个封闭的无流内陆盆地, 远离海洋, 海拔高,自然条件垂直变化明显。降水量自东向西递减, 东部年均降 水量 50-170mm, 西部为 $10-25 \mathrm{~mm}$ 。年均气温东部 $2-4^{\circ} \mathrm{C}$, 西部为 1.5-2.5 ${ }^{\circ} \mathrm{C}$ 。干燥度大, 降水稀少, 蒸发强烈, 蒸发量 2000-3000mm。大 风日数频繁, 平均风速 $4 \mathrm{~m} / \mathrm{s}$, 最大风速 $20 \mathrm{~m} / \mathrm{s}$, 芒崖曾出现过 $40 \mathrm{~m} / \mathrm{s}$ 的大风。龙卷风也很强,高达 $100-200 \mathrm{~m}$ 。

1.1.4 土壤和植被因素

盆地内主要土壤类型是棕钙土、灰棕漠土、草甸土、沼泽土和 盐土。柴达木盆地属温带灌木、半灌木荒漠类型。由于盆地中气候 自东向西变化, 地貌基质、潜水和盐分成环带状递边特点, 有如下植 被组合与分布特点。茶卡盆地与香日德的土托山以东, 植被有草原 化荒漠性质,地带性土壤为棕钻土。在沙砾质的洪积扇上, 分布着红 沙、木本猪毛菜, 细枝盐爪爪等为主的荒漠群系。多数盐化的土地 段上分布着具有景观外貌意义的苃苃草, 白刺和梭梭。前山带山坡 则为驼线䓠、合头草、蒿时猪毛菜、尖叶盐爪爪、黄苍、冰草、冷高、
第 1 卷 第 1 期 版本 1.0 2019年 12 月 8 日 文章类型: 论文 1 刊号( ISSN):2705-0637

节中蒿等荒漠草原种介人;盆地中部植被呈带状分布,昆仑山麓的 洪积倾斜平原,上部为光裸无植被的砾石戈壁, 砾面仅有壳状地衣。 中下部沙砾质戈壁上有旱生灌木、半灌木为主构成地带性荒漠群 系: 驼线㢣、膜果麻黄、红沙、尖叶盐爪爪、木本猪毛草, 沙拐束、中 亚木紫苑和梭梭等。在洪积扇下部, 分布有疏花柽柳、白刺、黑果枸 杞与细枝盐爪爪等构成盐化灌丛沙堆, 尤以柽柳丛下的大型沙堆 为显著标志。丘间低地分布着芦苇与大叶白麻为主的盐草甸, 并有 锁阳等生于白刺根部。在沙滩带以北是广阔的盐化草甸, 建群种为 芦苇和赖草, 混有白刺、黑果枸杞等盐生灌木, 亦有大叶白麻、罗布 麻等。在潜水出露的沼泽化地段, 则为水麦冬、海乳草、西伯利亚苶 等构成盐沼泽。在盆地中心低凹的盐湖, 湖滨无植被的盐滩, 它的边 缘是草丘盐沼泽。盆地西南部的祁漫山前洪积扇上覆盖着大片流 沙, 仅边缘部分有稀疏的柴达木沙拐本、膜果麻黄和柽柳灌丛沙 滩; 柴达木北部阿尔金山麓的碎石质坡地和沙砾质洪积扇上, 仍为 红沙、合头草、细枝盐爪爪、驼线藜、蒿叶猪毛菜等为主的半灌木荒 漠植物分布。

总之, 从中新世纪开始的喜玛拉雅动和第四纪的青藏高原剧 烈抬起,迫使大气环流改变格局,干旱程度加大,干季与风季周期发 生, 荒漠、戈壁不断扩大, 出现荒漠景观。植被向着强度旱生荒漠类 型发展,形成耐极端干旱的盆地半灌木、灌木荒漠和耐盐植被。

\section{2 人为因素}

在自然状态下, 土地荒漠化演变速度是较缓慢的,需要千百年 甚至更长时间才能显示其变化。但人类社会不合理的生产活动, 破 坏了生态平衡,加剧了荒漠化的发展进程。柴达木盆地荒漠区 1949 年解放初期总人口 1.95 万人, 经过 50 多年的发展, 人口增加到 29.6 万人 (农业人口 9.0 万人)。随着人口的增加, 人为破坏自然环 境的作用更加明显。盆地 1950 年耕地面积只有 $969.8 \mathrm{hm}^{2}$ 到 1995 年耕地已达 3.85 万公顷,仅 1954 年 -1974 年的 20 年间共旺荒 8.7 万公顷土地。实际耕种的只有 $30666.7 \mathrm{hm}^{2}$ 。大多是中低产田, 总产 量在 8-9 万吨,耕地逐渐变为半固定沙地和流动沙地。1966-1989 年盆地中沙区植被 120.5 万公顷被破坏。1959-1994 年,35 年间增 加至 $467.78 \mathrm{hm}^{2}$ 平均每年增加 $13.37 \mathrm{hm}^{2}$, 年增加率 $2.2 \%$, 荒漠化程 度明显加剧,呈不断扩大的趋势。

\section{2 荒漠化土地危害}

土地沙漠化的主要危害是风蚀,风沙、沙尘和沙丘前移等。

2.1 对农牧业生产危害。一是可利用土地面积缩小; 二是土地 质量下降, 具有较高的肥力的土壤层, 长期遭受风蚀, 表层有机质、 氮、磷、钾和物理粉粒成分, 不断地被吹失, 加之积沙使土地逐渐贫 痊化; 三是牲畜处于饥饿、半饥饿状态, 平均体重明显减少。从解放 初期到现在每只羊由 $20-25 \mathrm{~kg}$ 减为 $15 \mathrm{~kg}$ 左右; 乌兰、都兰、德令哈 风沙对农业生产危害更为严重, 1997 年 5 月 25 日和 6 月 1 日德令 哈地区大风持续 8 小时以上, 作物受害面积 1300 多公顷。乌兰县 五十年代后期在草地上是荒 6667 公顷, 进人六十年代后耕地逐渐 沙化, 不能不退耕还牧。地处都兰县的诺木洪农场 1960 年 3 月 19 日有 20 公顷耕地表土被大风吹走 3-4 厘米,26 公顷的春播小麦种 籽被风吹跑。1979 年 4 月的一场大风,共和县黑马河乡加隆村 200 多只羊被卷人青海湖淹死, 共和县在这次大风中死亡牲畜 2700 只。

\section{2 对地面建筑物的危害}

格尔木农场由于风沙危害每年用于清理田埂渠道积沙的工日 达 3.98 万个。都兰县西北的流沙每年以 8-12 米的速度向城内移 
动,直接威胁着县城,严重影响着居民的正常生活和人身健康。共和 县沙珠玉乡上卡力岗村一百多户四十多年来, 因流沙埋压房屋,被 迫搬迁三次,珠玉村有 27 户庄廓被沙子埋没。

2.3 对交通道路的危害

由于风沙流受阻堆积和沙丘前移埋压路面是经常发生的,青 藏铁路沙害累计里程 $176.86 \mathrm{~km}$ 。主要危害是沙埋线路,几乎常年都 有沙埋现象轻者道心积沙,重者沙埋超过轨面 40 厘米。1 1985 年 5 月伏沙梁地区沙埋超过轨面 70 厘米,有 4 趟列车被阻隔在伏沙梁 地区。由风沙弥漫,影响了望,无法看青信号,经常发生列车停运、晚 点现象。1984 年 5 月 13 日在客城 K454+200 处, 由于大风使沙子 上道埋没道轨,造成了次货运列车脱轨, 破坏线路 125 米,中断行车 25 小时 34 分。此外对线路道岔设施的破坏也很严重,长年风沙,使 路基不断被剥蚀,严重是路基被毁,枕木悬空,桥涵堵塞。全省沙区 青藏铁路,青藏公路,青新公路等国道、省道,沙漠化危害道路长达 $4046 \mathrm{~km}$,其中严重路段 $812.8 \mathrm{~km}$,年损失人民币约 600 万元。

2.4 对生活环境的危害

每当冬春刮大风时,从沙区卷塌的尘暴遮天盖地,旷野 2-3 米 内看不清景物,甚至白天室内要开灯,汽车行驶开着车灯。柴达木盆 地除大柴旦、德令哈等少数地形比较闭塞的地方外,月平均风速都 在 3 米/秒以上,盆地中部在 4 米/秒, 芒崖高达 5 米/秒, 是青海风 力最强的地方,沙尘暴日数一般在 8-15 日,最多达 39 天,沙尘暴使 大气混浊,妨碍了人类生产活动,严重污染空气和饮水、食物,对人 类健康产生直接危害。

总之,沙漠化对人类生产、生活的危害是诸多方面,仅危害农牧 业生产、交通和村镇几个方面估算,年经济损失约 5 亿元人民币。

\section{3 沙化土地治理对策}

青海省治沙工作起步较晚 1959 年成立治沙委员会,下设办公 室和治沙队,与中科院治沙队等单位联合开始全省沙漠进行考察。 1961 年在盆地托拉亥等地进行了 13 个项目治沙试验。1962 年上 述机构相继撤消。1959 年 5 月成立省沙珠玉治沙试验站,到 1961 年进行了 9 次治沙定位研究, 到 1971 年已建立 103.8 公顷治沙样 板田, 设置沙障 14.3 公顷,长 12.6 万米,营造固沙林 49.1 公顷, 次后 每年以营造 13.3 公顷防风固沙林进行治理, 取得不少治沙成果, 沙 珠玉乡已成全国治理沙林区先进典型。都兰县宗巴滩历史上植被 好,沙生灌木覆盖度为 15-50\%,后来遭到严重破坏,盖度仅有 $0.4 \%$, 1981 年建立沙生植物保护站,进行封沙育林(草), 经 10 年多努力, 到 1994 年植物盖度平均增加 $15.8 \%$ 。经过 30 年的实践,取得不少 经验,为今后沙漠化土地防治提供科学依据。但缺少治沙防沙和开 发研究工作及技术的推广应用。

3.1 提高认识,加强领导

防沙治沙是一项系统的生态工程,是造福后代的大事。江总书 记指出: “在现代化建设中, 必须把现实可持续发展作为一个重大 战略。要把控制人口、节约资源、保护环境放到重要位置,使人口增 长与社会生产力的发展相适应, 使经济建设与资源环境相协调, 现 实良性循环。”1991 年以来国务院两次召开全国防沙治沙工作会 议,江泽民、李鹏两次致信,陈俊生国务委员两次到会并作重要讲 话,极大地鼓舞了沙区广大干部群众,得到社会普遍关注。认真贯彻 落实中央领导的指示, 对高寒荒漠区的我省来说,具有特殊重要的 意义。首先是抓好领导干部的防沙、治沙责任制、层层建立目标责 任制。认真落实各级领导任期防沙治沙目标责任制, 严明奖惩, 确保 任务完成。继续坚持各级党政领导办防沙治沙绿化点的做法,抓典
第 1 卷 第 1 期 版本 1.0 2019 年 12 月 8 日 文章类型: 论文 | 刊号( ISSN):2705-0637

型、树样板,总结经验,指导全面,推动本地区防沙治沙、绿化事业的 发展。各级政府要逐步增加防沙治沙建设的投人,这点是非常重要, 它是搞好防沙治沙的重要保障。各级绿委是统一领导本地区本部 门绿化工作的机构, 是各级政府的参谋, 职能部门,在防沙治沙工作 中, 要充分发挥应有的规则,组织协调、督促检查,评比表彰的职能, 认真履行好职责。

3.2 广泛发动群众,大力开展防沙治沙工程, 掀起全民防沙治沙 的新局面

防沙治沙是一项利国利民的公益事业，具有广泛的社会性和 全民性,义务性和法制性。搞好治沙防沙工作,对开发柴达木资源、 改善投资环境有着十分重要的意义。要认真总结我省开展防沙,治 理工程以来的经验教训, 注意研究在改革开放和发展社会主义市 场经济新形势下,治沙工程所遇到的新情况,新问题,切实采取经济 的、行政的、舆论饿综合办法,加快我省治沙进程的步伐。城乡防沙 治沙工作要统筹规划的基础上,落实责任,要与建设文明乡镇、文明 村结合起来,铁路、交通等有关部门要各负其责,根据省上的要求抓 好防沙治沙和绿色通道建设及住地绿化工作（包括工作区和生活 区)。同时提倡有能力的工厂、企业、机关到附近的农村承包沙荒治 理,与农村扶贫、产业化经营结合起来,政策上给予优惠,实行利益 分成,谁治谁有,千方百计动员全社会积极投身防沙治沙伟大事业。

3.3 建立和充实治沙机构,广开筹资渠道、加大投资力度

在省政府领导下,由省绿化委员会、省林业局主管,建立由有关 部门组成治沙工作协调小组, 研究和协调解决治沙工作中重大问 题,荒漠区、县、市各级也组建领导机构。切实健全沙区林业机构,加 快乡、镇林业站(治沙站)建设, 并尽快建立乡镇沙漠化土地档案, 并 设专职和兼职沙漠化土地监测员。

防沙治沙在国民经济中属投资大、周期长、风险多、经济效益 低的产业,在高寒荒漠化情况下,防沙治沙工作需国家在宏观调控 中给予保护和扶持,需要各行各业的支持。青海省林业的总体经济 实力差,林业总产值在农牧业产值中比重一般在 2-4\%之间。在指 导思想上单纯靠林业自身的力量积累资金, 封闭式的自我循环,寻 求发展是不可能的。况且我省地处江河源头和一部分荒漠地区,林 业建设基本上是生态建设,经济效益比较低。因此,我省的防沙、治 沙在可预见的时期内,还必须先靠较大规模的资金投人。盆地各部 门特别是财政、计划、水利、交通、农业开发、金融等在安排农业项 目时,要有一定比例的资金用于防沙治沙工程建设。

3.4 依靠科技进步、振兴沙产业

科技进步是沙产业建设的生命线, 我省虽然是八大沙漠之一, 对沙产业的发展,仍停留在粗放型的传统模式上,与国内其它沙区 来比,都处在低水平上。在沙产业建设中要把科技放在突出位置。 一是大力推广先进实用技术; 二是开展科技集团承包,即按区域、 项目组织科技承包集团,行政、技术、物资配套、责、权、利结合,资 金,任务、人员挂钩,开展全程技术的承包,培养一批各具特色的科 技示范典型; 三市重视科技人才的培养,搞好全员培训,特别是加强 对基层站、场、戋工作一线人员的培训,提高他们的业务素质和工 作水平; 四是注重科研工作,坚持多部门联合,组织农、林、牧、气、农 机等各业科技人员,协作攻关;五是加大对科技的投人。林业基本 建设,重点工程投资。育林基金、林业贴息贷款等,都要有一定比例 用于技术推广和技术开发,促进科技成果尽快向现实生产力转化。

3.5 紧密结合退耕还林(草)搞好沙产业经营模式中的果品类 经营模式 - 药材类经营模式 - 乔灌枝茎纺织材料经营模式的建设 
柴达木盆地沙区具有丰富的光能、热能、风能资源。可以举办各种 风力发电, 太阳能发电装置, 提高资源利用率。另外, 枸杞、白刺、沙 棘、罗布麻、大蒜等经济植物, 要规模化生产, 通过优化种植业结构, 优化投资结构达到低投入、低消耗、高效益之日的。按地区、县、乡、 村要各有产业和产品的重点发展方向。农、林、牧户以及其他各类 生产户要逐步由小而全或由简单的原料加工走上以一业为主的专 业化、集约化、科技化的规模经营形式,从而形成群体组成的知识 密集型的工业化生产方式, 形成规模产品, 产生规模效益, 达到持续 发展之经营目标。

3.6 实施依法治沙、依法治林战略,切实加强沙区植被资源的 保护管理

随着林业立法工作步骤的加快和林业法律体系的建立完善, 林业执法与执法监督工作就显得尤为重要。要继续强化依法治沙、 治林, 依靠林业法规管理沙区植被, 保护生态环境和野生动植物资 源。青海省经人大批准颁布实施的林业法规有 10 部,但有法不依、 执法不严的现象仍然存在。为此, 今后一个时期林业法制建设在完 善的同时, 重点抓好普法和执法两个环节, 提高全民、特别是各级领 导的执法观念, 加强执法检查力度, 发挥林业法规的权威性、严肃 性,为防沙治沙、沙产业的发展服务,全面实现依法行政、依法治沙
和依法振兴沙产业的目标。尤其是柴达木盆地开发中要把治沙作 为一种保护性产业, 提高到关系人们生存的高度认识, 列人各项开 发建设的重要内容,促进沙区生产发展。

致谢: 本论文撰写过程中得到青海省林业调查规划院院长董 得红、林建才主任和张胜邦处长的精心指导,得到我系杨春江老师 和田丰老师的大力支持和协助, 以及得到陈贵林、张子祥等同学的 热心帮助在此一并谢过。

\section{[参考文献]}

[1]田广庆, 赵鹏祥. 青海柴达木地区荒漠化现状及防治对策 [J].黑龙江畜牧兽医,2012(2):171。

[2]蒲永国, 方顺宝, 汪荣. 青海荒漠化现状及技术防治措施 [J]. 国土绿化,2002(08):46.

[3]吕嘉. 柴达木沙漠化现状及防治对策[J].柴达木开发研究, 2003(3):43-45.

[4]陈文俊,杨德福.青海省沙漠化土地现状及发展趋势与防治 对策[J].青海农林科技,2000(02):21-23.

[5]王发科,荷日多杰,祁贵明.柴达木盆地气候变化对荒漠化的 影响[J].千旱气象,2007,25(3):28-33.

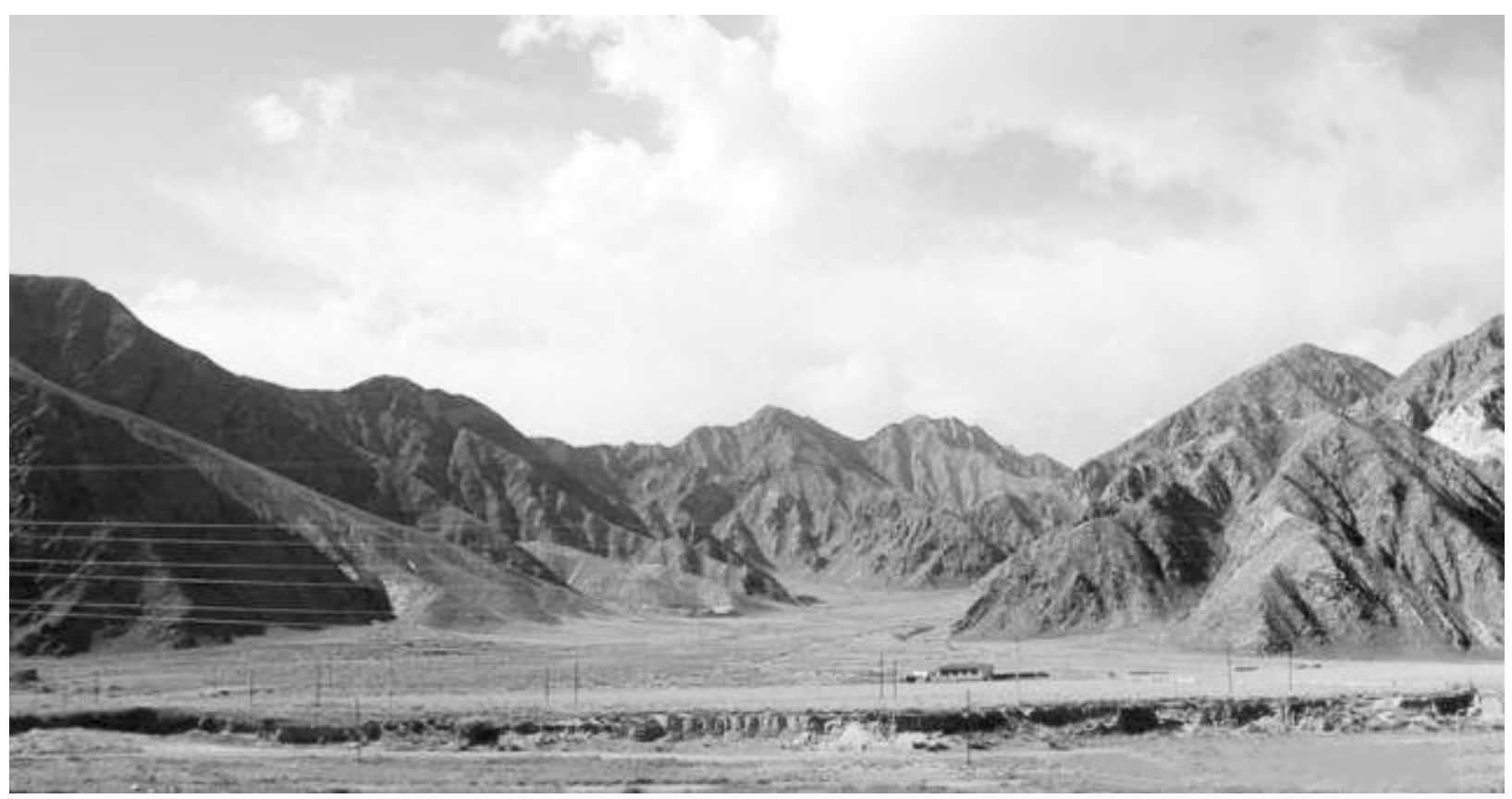

